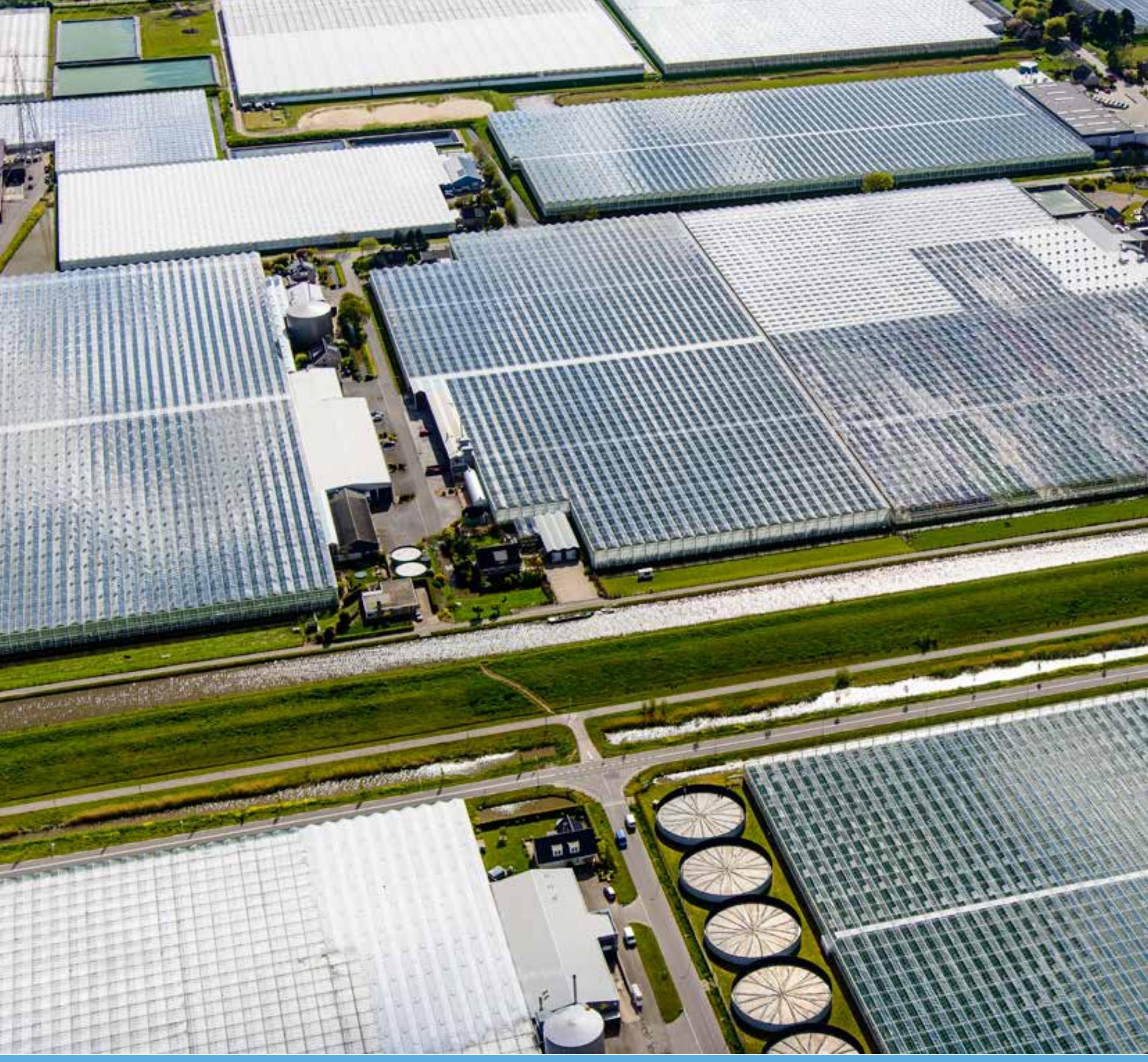

Nulmeting Regionale Energiemonitor Glastuinbouw Greenport West-Holland

Nico van der Velden en Pepijn Smit

WAGENINGEN
$\square$ UNIVERSITY \& RESEARCH 



\section{Nulmeting Regionale Energiemonitor Glastuinbouw Greenport West-Holland}

Nico van der Velden en Pepijn Smit

Dit onderzoek is uitgevoerd door Wageningen Economic Research in opdracht van en gefinancierd door Provincie Zuid Holland

Wageningen Economic Research

Wageningen, juni 2019

NOTA

2019-060 
Nico van der Velden en Pepijn Smit, 2019. Nulmeting Regionale Energiemonitor Glastuinbouw Greenport West-Holland. Wageningen, Wageningen Economic Research, Nota 2019-060. 16 blz.; 4 fig.; 5 tab.; 12 ref.

De Nederlandse glastuinbouw werkt aan reductie van de $\mathrm{CO}_{2}$-emisisie. De $\mathrm{CO}_{2}$-emissie kan worden verlaagd langs twee hoofdlijnen: energiebesparing (vraagreductie) en energievoorzieningen zonder $\mathrm{CO}_{2}$-emissie. $\mathrm{Bij}$ dit laatste gaat het om de inzet van duurzame energie en de inkoop elektriciteit en warmte. Dit wordt vooral op regionaal niveau gerealiseerd.

Partijen binnen Greenport West-Holland hebben in 2017 een energieakkoord getekend met sectordoelen voor 2030 in de GPWH-gemeenten. Hiervoor is een nulmeting uitgevoerd waarbij gebruik is gemaakt van de ontwikkelde methodiek voor de regionale Energiemonitor glastuinbouw en is voortgebouwd op de Nationale Energiemonitor Glastuinbouw. In de nulmeting is de energiebalans, de $\mathrm{CO}_{2}$-emissie, het aandeel duurzame energie en het aandeel van de energievoorziening zonder $\mathrm{CO}_{2}$ emissie in GPWH voor 2016 gekwantificeerd.

Trefwoorden: Energie, glastuinbouw, monitor, Greenport West-Holland, energievraag, energievoorziening, $\mathrm{CO}_{2}$-emissie, duurzame energie

Dit rapport is gratis te downloaden op https://doi.org/10.18174/477937 of op www.wur. nl/economicresearch (onder Wageningen Economic Research publicaties).

(C) 2019 Wageningen Economic Research

Postbus 29703, 2502 LS Den Haag, T 07033583 30, E communications.ssg@wur.nl, www.wur.nl/economic-research. Wageningen Economic Research is onderdeel van Wageningen University \& Research.

\section{(cc) BY-NC}

Dit werk valt onder een Creative Commons Naamsvermelding-Niet Commercieel 4.0 Internationaallicentie.

(C) Wageningen Economic Research, onderdeel van Stichting Wageningen Research, 2019 De gebruiker mag het werk kopiëren, verspreiden en doorgeven en afgeleide werken maken. Materiaal van derden waarvan in het werk gebruik is gemaakt en waarop intellectuele eigendomsrechten berusten, mogen niet zonder voorafgaande toestemming van derden gebruikt worden. De gebruiker dient bij het werk de door de maker of de licentiegever aangegeven naam te vermelden, maar niet zodanig dat de indruk gewekt wordt dat zij daarmee instemmen met het werk van de gebruiker of het gebruik van het werk. De gebruiker mag het werk niet voor commerciële doeleinden gebruiken.

Wageningen Economic Research aanvaardt geen aansprakelijkheid voor eventuele schade voortvloeiend uit het gebruik van de resultaten van dit onderzoek of de toepassing van de adviezen.

Wageningen Economic Research is ISO 9001:2008 gecertificeerd.

Wageningen Economic Research Nota 2019-060 | Projectcode 2282200467

Foto omslag: Siebe Swart/Hollandse Hoogte 


\section{Inhoud}

Samenvatting en conclusies $\quad 5$

1

$\begin{array}{ll}\text { Inleiding } & \mathbf{7}\end{array}$

2

$\begin{array}{ll}\text { Resultaten nulmeting } & 9\end{array}$

$2.1 \quad$ Areaal glastuinbouw $\quad 9$

2.2 Energie-input en -output 9

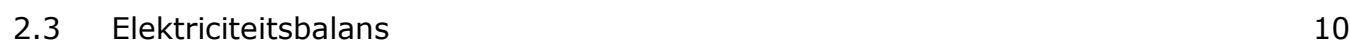

2.4 Energie per $\mathrm{m}^{2}$ kas 11

$\begin{array}{lll}2.5 & \text { Energie-indicatoren } & 11\end{array}$

$\begin{array}{ll}\text { Literatuur en websites } & 14\end{array}$

Bijlage 1 Gemeenten per deelregio in GPWH $2016 \quad 15$ 



\section{Samenvatting en conclusies}

Glastuinbouw en reductie $\mathrm{CO}_{2}$-emissie

In Nederland wordt door vele partijen gewerkt aan reductie van de $\mathrm{CO}_{2}$-emisisie, zo ook de glastuinbouw. Hiervoor wordt door het ministerie van Landbouw, Natuur en Voedselkwaliteit (LNV) en Glastuinbouw Nederland samengewerkt binnen het Programma Kas als Energiebron (KaE).

De $\mathrm{CO}_{2}$-emissie kan worden gereduceerd langs twee hoofdlijnen: energiebesparing (vraagreductie) en energievoorziening zonder $\mathrm{CO}_{2}$-emissie. Dit laatste betreft de inzet van duurzame energiebronnen en de inkoop warmte en elektriciteit in combinatie met de benodigde externe $\mathrm{CO}_{2}$-voorziening. Door het bedrijfsoverstijgende karakter is de tweede hoofdlijn afhankelijk van activiteiten op regionaal niveau.

Regionale organisaties zoals de Greenport West-Holland (GPWH) zijn ook actief om tot reductie van de $\mathrm{CO}_{2}$-emissie te komen. In 2017 hebben 35 partijen binnen de GPWH een energieakkoord getekend met sectordoelen voor 2030 in de GPWH-gemeenten. GPWH heeft Wageningen Economic Research gevraagd een nulmeting uit te voeren voor de GPWH-regio. Hiernaast heeft KaE gevraagd om een conceptueel raamwerk te ontwikkelen voor een Regionale Energiemonitor Glastuinbouw.

Voor het raamwerk voor de Regionale Energiemonitor Glastuinbouw is voortgebouwd op de Nationale Energiemonitor Glastuinbouw die door Wageningen Economic Research jaarlijks wordt uitgevoerd voor KaE. De nulmeting voor GPWH is gemaakt op basis van dit conceptueel raamwerk (Van der Velden en Smit, 2019). Binnen GPWH zijn de deelregio's West, Oost en Zuid in beschouwing genomen.

\section{Nulmeting}

Areaal

- In GPWH bevindt zich in 2016 46\% van het glastuinbouwareaal in geheel Nederland. De deelgebieden West, Oost en Zuid omvatten respectievelijk 29, 14 en 3\% van het landelijk areaal. In GPWH is er relatief meer sierteeltareaal en minder areaal voedingsglastuinbouw. In West en Oost is er iets meer sierteelt. In Zuid heeft groente de overhand.

\section{Energie}

- In 2016 bedroeg het totaal netto-energiegebruik van de glastuinbouw in GPWH 51 PJ. Dit was iets meer dan de helft van het netto-energiegebruik van de glastuinbouw in Nederland. Het energiegebruik bestaat vooral uit aardgas, gevolgd door inkoop elektriciteit en in mindere mate uit duurzame energie en inkoop warmte.

- Duurzame energie omvat in GPWH $80 \%$ warmte en $20 \%$ elektriciteit. Duurzame warmte bestond voor $70 \%$ uit aardwarmte, gevolgd door herwonnen zonnewarmte (26\%) en inkoop duurzame warmte (4\%). Duurzame elektriciteit werd bijna volledig ingekocht. De inkoop van warmte zat in deelregio Oost.

- Uit het gemiddeld energiegebruik per $\mathrm{m}^{2}$ kas blijkt dat in de glastuinbouw in GPWH gemiddeld energie-intensievere gewassen werden geteeld dan in geheel Nederland. Binnen GPWH gold dat voor de deelregio's West en Oost. In Zuid werden gemiddeld extensievere gewassen geteeld. Hierbij is ook het gebruik van belichting van invloed.

- Er werd meer elektriciteit verkocht dan er werd ingekocht waardoor de glastuinbouw in GPWH netto leverancier van elektriciteit was. Dit gold ook voor de afzonderlijke deelregio's.

\section{Energievoorziening zonder $\mathrm{CO}_{2}$-emissie}

- Het aandeel van de totale energievoorziening zonder $\mathrm{CO}_{2}$-emissie in het totaal netto-energiegebruik omvat duurzame energie, inkoop warmte en inkoop elektriciteit. ${ }^{1}$ Dit aandeel is in GPWH met $18,9 \%$ groter dan in de Nederlandse glastuinbouw $(17,8 \%)$. In Oost $(29,8 \%)$ zat dit erboven en in West

\footnotetext{
1 Ter voorkoming van dubbeltellingen zijn de laatste 2 elementen exclusief duurzame energie.
} 
$(14,8 \%)$ en in Zuid $(9,1 \%)$ zat dit eronder. Dit komt vooral door de inkoop van warmte in Oost. Daarnaast is ook het aandeel duurzame energie in Oost groter.

- Het aandeel duurzame energie in het totaal energiegebruik bedroeg in 2016 in GPWH 5,1\%. Dit was lager dan in de gehele Nederlandse glastuinbouw $(5,4 \%)$. In de deelregio Oost lag dit hoger $(6,9 \%)$ en in West $(4,6 \%)$ en in Zuid $(2,5 \%)$ lager.

- Het aandeel inkoop warmte was in GPWH $(4,1 \%)$ hoger dan in de gehele Nederlandse glastuinbouw $(3,7 \%)$. Door het warmteleveringsproject zat inkoop warmte volledig in deelregio Oost. In deelregio Oost bedroeg het aandeel $13,5 \%$.

- Het aandeel inkoop elektriciteit was in GPWH $(9,7 \%)$ hoger dan in de glastuinbouw in Nederland $(8,7 \%)$. In de deelregio's West en Oost lag dit aandeel boven dat van de Nederlandse glastuinbouw en in Zuid eronder.

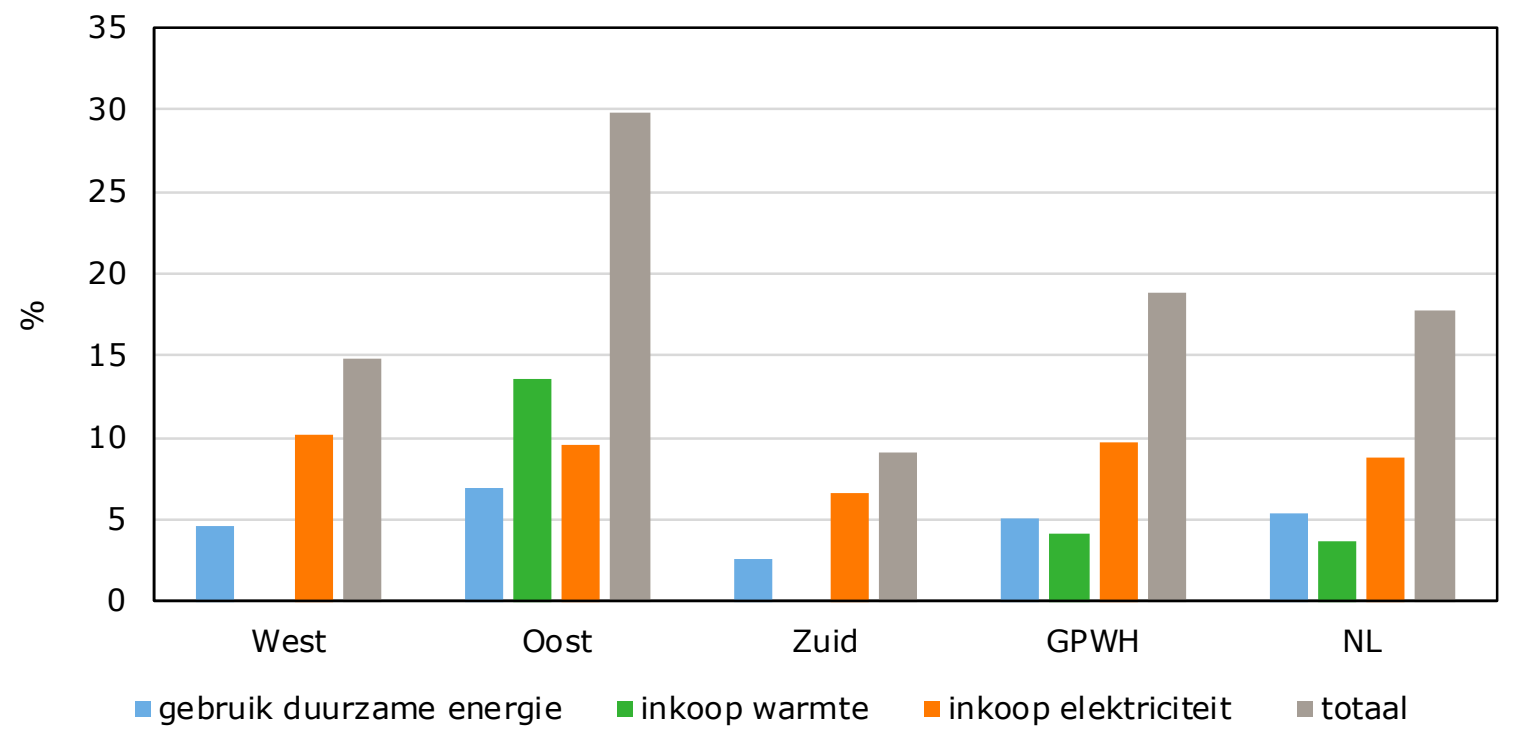

Figuur S.1 Aandelen energievoorziening zonder $\mathrm{CO}_{2}$-emissie in het netto energiegebruik in GPWH en Nederland

\section{$\mathrm{CO}_{2}$-emissie}

- De $\mathrm{CO}_{2}$-emissie in de glastuinbouw in GPWH bedroeg in 2016 2,8 Mton en omvatte 49\% van de $\mathrm{CO}_{2}$ uitstoot van de Nederlandse glastuinbouw als geheel. Dit aandeel was groter dan het aandeel in het areaal (46\%). Dit komt door de gemiddeld hogere energievraag en het hogere aandeel van de energievoorziening zonder $\mathrm{CO}_{2}$-emissie in GPWH. De grotere energievraag werd daarbij niet geheel gecompenseerd door de grotere energievoorziening zonder $\mathrm{CO}_{2}$-emissie.

- In deelregio West was het aandeel in de landelijke $\mathrm{CO}_{2}$-emissie van de glastuinbouw 33\%, in Oost is dat $13 \%$ en in Zuid 3\%. In West was dit aandeel groter dan het aandeel in het landelijke areaal en in Oost is dat kleiner. Ook deze verschillen tussen de deelregio's hangen samen met de energieintensiteit per $\mathrm{m}^{2}$ en het aandeel van de energievoorziening zonder $\mathrm{CO}_{2}$-emissie. 


\section{$1 \quad$ Inleiding}

\section{Glastuinbouw en $\mathrm{CO}_{2}$-emissie}

In Nederland wordt door vele partijen zowel nationaal als regionaal gewerkt aan reductie van de $\mathrm{CO}_{2}$ emisisie. In de Meerjarenafspraak Energietransitie Glastuinbouw 2014-2020 is een doelstelling voor de $\mathrm{CO}_{2}$-emissie van de glastuinbouw overeengekomen van 4,6 Mton in 2020. Een $\mathrm{CO}_{2}$-doel voor de glastuinbouw in 2030 kan een onderdeel zijn van het in ontwikkeling zijnde Klimaatakkoord. In het Programma Kas als Energiebron (KaE) wordt door de Nederlandse glastuinbouw en de rijksoverheid samengewerkt om het $\mathrm{CO}_{2}$-sectordoel te realiseren.

\section{Regionale organisaties}

Regionale organisaties zoals de Greenport West-Holland (GPWH) zijn ook actief op het terrein van reductie van de $\mathrm{CO}_{2}$-emissie. Hierover zijn afspraken gemaakt in het Energieakkoord voor duurzame groei en deze bijdragen van regionale organisaties zullen waarschijnlijk een belangrijk onderdeel zijn in het in voorbereiding zijnde Klimaatakkoord. De partijen binnen GPWH willen graag een bijdrage leveren aan klimaat- en duurzaamheidsdoelstellingen door middel van concrete projecten. In 2017 hebben 35 partijen binnen GPWH een energieakkoord getekend met sectordoelen voor 2030 in de GPWH-gemeenten. In dit akkoord is ook afgesproken deze energiedoelen te monitoren waarbij het gaat om de energieontwikkelingen op glastuinbouwbedrijven en op agro gerelateerde bedrijven in GPWH als geheel en een aantal deelregio's binnen GPWH.

\section{Reductie $\mathrm{CO}_{2}$-emissie}

De $\mathrm{CO}_{2}$-emissie kan worden gereduceerd langs twee hoofdlijnen: energiebesparing (vraagreductie) en het gebruik van energievoorzieningsopties zonder $\mathrm{CO}_{2}$-emissie. Dit laatste betreft de inzet van duurzame energiebronnen en de inkoop van warmte en elektriciteit in combinatie met de benodigde externe $\mathrm{CO}_{2}$-voorziening. Vanwege het bedrijfsniveauoverschrijdende karakter is vooral het succes van de tweede hoofdlijn afhankelijk van activiteiten op regionaal niveau. Om ontwikkelingen en bijdragen in regio's te volgen, de bijdrage aan klimaat en duurzaamheidsdoelstellingen te kwantificeren en beleidsmatige afwegingen te ondersteunen is een monitor van de regionale energie- en $\mathrm{CO}_{2}$ emissieontwikkelingen in de glastuinbouw van belang.

\section{Nationale Energiemonitor Glastuinbouw}

Wageningen Economic Research voert jaarlijks in opdracht van het ministerie van LNV en Glastuinbouw Nederland, samen vertegenwoordigd in het innovatieprogramma KaE, de Energiemonitor van de Nederlandse Glastuinbouw uit (Van der Velden en Smit, 2018a). In de nationale monitor worden de energie-indicatoren $\mathrm{CO}_{2}$-emissie, energie-efficiëntie, aandeel duurzame energie en aandeel energievoorziening zonder $\mathrm{CO}_{2}$-emissie van de glastuinbouw op sectorniveau gemonitord. Bovendien worden door analyse over een reeks van jaren, de achterliggende factoren en de ontwikkelingen geduid. Met de inzichten uit de nationale Energiemonitor Glastuinbouw worden ook toekomstprognoses op nationaal niveau (Van der Velden et al., 2018) en in combinatie met regio-specifieke input ook op regionaal niveau (Smit en Van der Velden, 2018) (Smit en Van der Velden, in voorbereiding) gemaakt.

Voor het monitoren van de indicatoren wordt jaarlijks een energiebalans van de glastuinbouwsector in Nederland opgesteld op basis van empirische data uit een reeks van bronnen. De Energiemonitor Glastuinbouw wordt sinds 1990 jaarlijks gepubliceerd en deze publicatie is sinds 2009 vergezeld van het bijbehorende Protocol (Van der Velden en Smit, 2018b). In het Protocol zijn de definities, de conceptuele methodiek, de gebruikte databronnen en de werkwijze vastgelegd.

Vragen van Greenport West- Holland en Kas als Energiebron

GPWH heeft Wageningen Economic Research gevraagd om een nulmeting van een Regionale Energiemonitor Glastuinbouw voor de regio GPWH voor het jaar 2016 uit te voeren. Daarnaast heeft het programma Kas als Energiebron Wageningen Economic Research gevraagd om een conceptueel 
raamwerk te ontwikkelen waarmee de ontwikkelingen rondom energie en $\mathrm{CO}_{2}$-emissie van de glastuinbouw regionaal kunnen worden gemonitord. Het is wenselijk hierbij zo veel mogelijk voort te bouwen op en gebruik te maken van de beschikbare informatie uit de landelijke Energiemonitor Glastuinbouw. Naast inhoudelijke afstemming brengt dit ook inhoudelijke diepgang en kostenefficiëntie met zich mee.

Met een Regionale Energiemonitor Glastuinbouw kunnen ook effecten van concrete projecten worden gekwantificeerd, achtergronden, samenhang en trends over meerdere jaren worden geanalyseerd en toekomstprognoses worden ontwikkeld. Deze activiteiten maken geen deel uit van deze nulmeting, maar liggen logischerwijs wel in het verlengde.

De nulmeting voor GPWH is gemaakt op basis van het conceptueel raamwerk voor de Regionale Energiemonitor Glastuinbouw. Dit raamwerk is gemaakt in opdracht van KaE en is beschreven in een aparte notitie (Van der Velden en Smit, 2019). In de nulmeting voor de glastuinbouw in GPWH zijn agro-gerelateerde bedrijven niet betrokken. In het vervolg wordt deze monitor benoemd als: Regionale Energiemonitor Glastuinbouw voor GPWH.

\section{Regio-indeling}

In de Regionale Energiemonitor Glastuinbouw voor GPWH is het areaal glastuinbouw in een reeks van gemeenten in beschouwing genomen (bijlage 1). Naast de Greenport als geheel zijn ook een drietal deelregio's van de greenport in beschouwing genomen, zie kaart. De indeling van de gemeenten naar deelregio's is ook opgenomen in bijlage 1 .

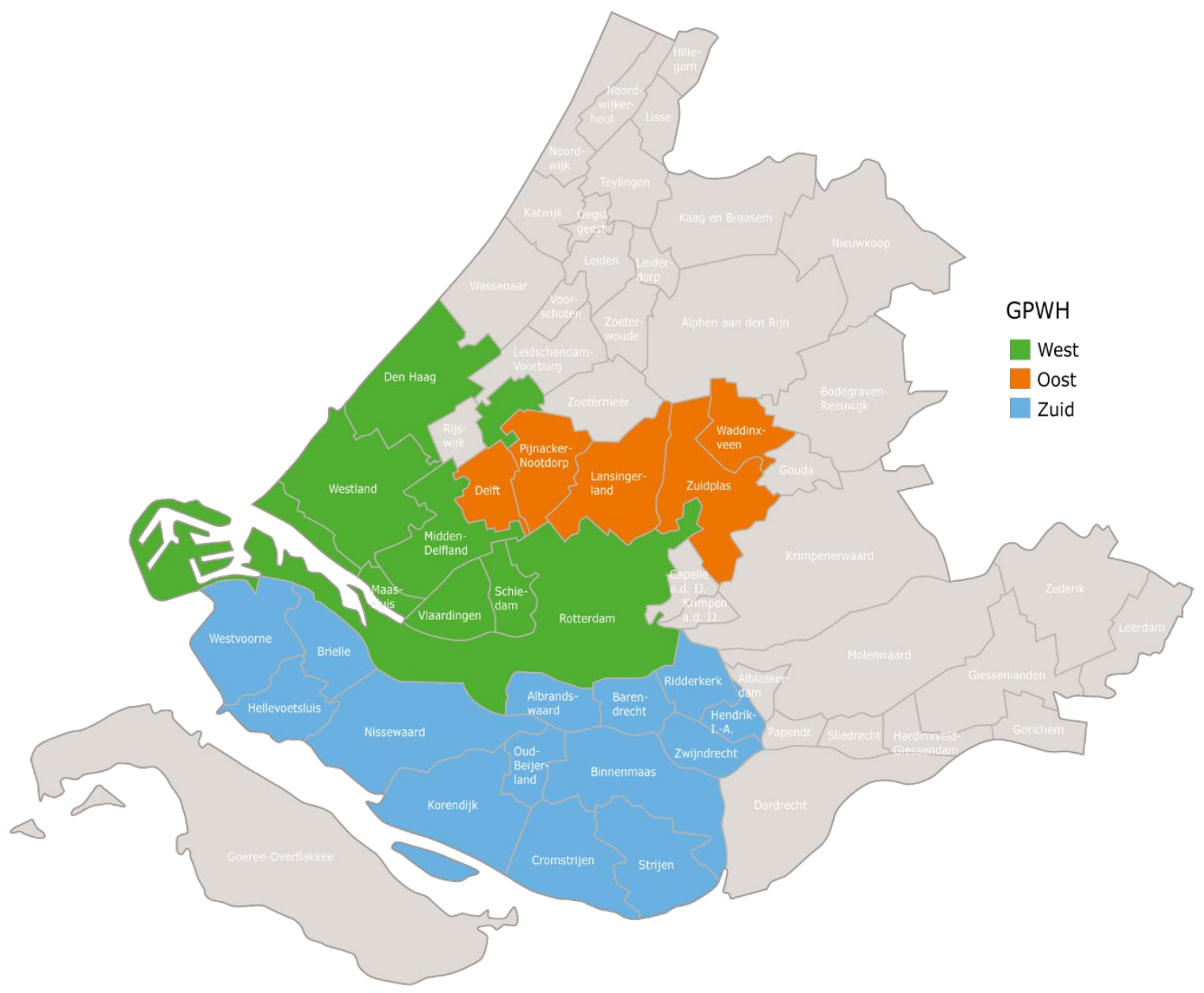

Figuur 1.1 Regionale indeling Regionale Energiemonitor Glastuinbouw Greenport West-Holland 


\section{$2 \quad$ Resultaten nulmeting}

\subsection{Areaal glastuinbouw}

De Nederlandse glastuinbouw omvatte in 2016 9.280 ha. Hiervan bevond zich $46 \%$ in het gebied van de GPWH (tabel 2.1). Voor dit project zijn binnen GPWH de deelgebieden West, Oost en Zuid onderscheiden. Deze drie omvatten in 2016 respectievelijk 29, 14 en 3\% van het landelijk areaal. Uit de verdeling over de subsectoren blijkt dat er in GPWH relatief minder areaal voedingsglastuinbouw en meer sierteeltareaal was in vergelijking met Nederland. In de afzonderlijke deelregio's van GPWH komt in West en Oost iets meer sierteelt voor. In deelregio Zuid heeft het groenteareaal met ruim driekwart de overhand (figuur 2.1). Uit (Smit en van der Velden, 2016) is gebleken dat in deelregio West het areaal met belichting zowel absoluut als relatief groter is.

Tabel 2.1 Areaal glastuinbouw per subsector in GPWH en in Nederland in 2016 (ha) (\%)

\begin{tabular}{|c|c|c|c|c|c|}
\hline \multirow[t]{2}{*}{ Subsector } & \multicolumn{4}{|c|}{ GPWH } & \multirow[t]{2}{*}{ Nederland } \\
\hline & West & Oost & Zuid & Totaal & \\
\hline Groente a) & $1.251(47 \%)$ & $625(48 \%)$ & $238(76 \%)$ & $2.114(49 \%)$ & $5.003(54 \%)$ \\
\hline Planten c) & $682(26 \%)$ & $285(22 \%)$ & $38(12 \%)$ & $1.006(23 \%)$ & $2.119(23 \%)$ \\
\hline Totaal a) & $2.674(100 \%)$ & $1.306(100 \%)$ & $313(100 \%)$ & $4.292(100 \%)$ & $9.281(100 \%)$ \\
\hline
\end{tabular}

a) omvat groente, fruit en uitgangsmateriaal; b) inclusief uitgangsmateriaal; c) omvat potplanten, perkplanten, boomkwekerij en vaste planten. Bron: CBS Landbouwtelling.

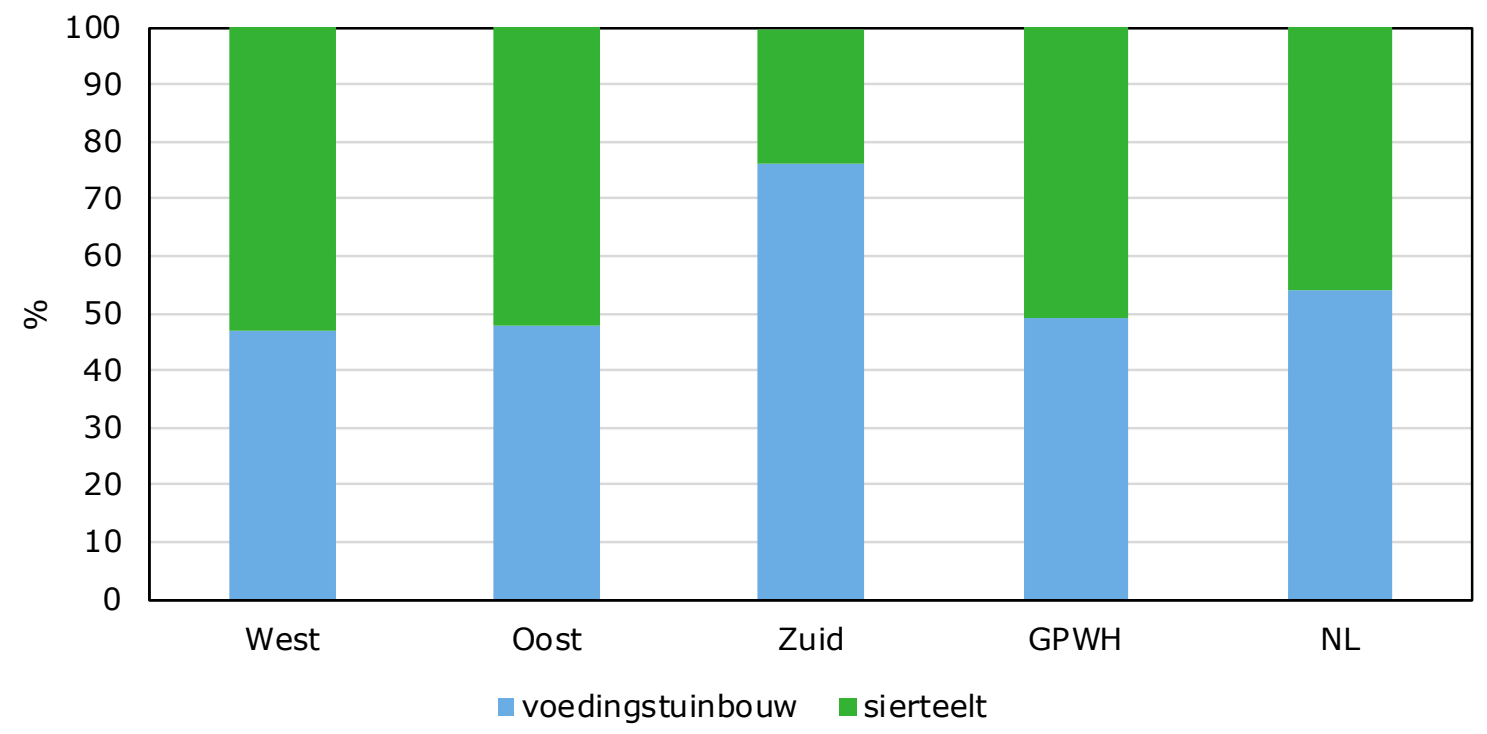

Figuur 2.1 Aandelen areaal voedingstuinbouw en sierteelt in GPWH en Nederland

\subsection{Energie-input en -output}

In GPWH bedroeg in 2016 het totale energiegebruik van de glastuinbouw $51 \mathrm{PJ}$ (tabel 2.2). Dit is iets meer dan de helft van het totaal energiegebruik van de glastuintuinbouw in Nederland. Binnen GPWH zit het grootste deel van het energiegebruik in deelregio West, gevolgd door Oost en Zuid. 
De energie-input bestond vooral uit aardgas en elektriciteit. De warmte-input (duurzaam en inkoop) heeft een beperkte omvang en zit vooral in regio Oost. Dit komt door het restwarmteproject in Oost. De totale elektriciteits-input in GPWH bestond in 2016 voor 9\% uit duurzame elektriciteit. Dit laatste werd voor $98 \%$ ingekocht en voor $2 \%$ geproduceerd met zonnecellen. De totale warmte-input in GPWH bestond in 2016 voor de helft uit inkoop warmte en voor de andere helft uit duurzame warmte. Duurzame warmte bestond voor $70 \%$ uit aardwarmte, $26 \%$ uit herwonnen zonnewarmte en $4 \%$ werd ingekocht. In geheel GPWH bestond in 2016 het gebruik van duurzame energie voor $80 \%$ uit warmte en voor $20 \%$ uit elektriciteit.

Tabel 2.2 Energie-input en -output glastuinbouw in GPWH en in Nederland in 2016

\begin{tabular}{|c|c|c|c|c|c|c|}
\hline \multirow[t]{2}{*}{ Energiesoort } & \multirow[t]{2}{*}{ Eenheid } & \multicolumn{4}{|c|}{ GPWH } & \multirow[t]{2}{*}{ Nederland } \\
\hline & & West & Oost & Zuid & Totaal & \\
\hline \multicolumn{7}{|l|}{ Input } \\
\hline Elektriciteit b) & Miljard kWh & 1,01 & 0,46 & 0,06 & 1,52 & 2,70 \\
\hline Warmte c) & PJ & 1,1 & 3,0 & $<0,1$ & 4,2 & 8 \\
\hline \multicolumn{7}{|l|}{ Output } \\
\hline Elektriciteit d) & Miljard kWh & 1,44 & 0,61 & 0,16 & 2,21 & 4,95 \\
\hline Warmte e) & PJ & 0 & $<0,1$ & 0 & $<0,1$ & $<0,1$ \\
\hline
\end{tabular}

a) inclusief overig fossiel $(<0,5 \%$ ); b) inclusief duurzame elektriciteit (inkoop en productie); c) omvat restwarmte, wkk van energiebedrijven en gebruik duurzame warmte; d) inclusief duurzame elektriciteit; e) inclusief duurzame warmte.

\subsection{Elektriciteitsbalans}

Uit de globale elektriciteitsbalans (tabel 2.3) blijkt dat in GPWH door de glastuinbouw in 2016 meer elektriciteit werd geproduceerd (4,08 miljard kWh) dan geconsumeerd (3,39 miljard kWh). De productie kwam bijna geheel voor rekening van aardgasgestookte wkk. Duurzame elektriciteitsproductie omvatte minder dan $1 \%$ van de totale productie. Meer dan de helft van de productie (2,23 miljard kWh) werd verkocht. Daarnaast werd ook 1,52 miljard kWh elektriciteit ingekocht.

Verder blijkt dat in geheel GPWH en in de deelregio's de verkoop van elektriciteit groter was dan de inkoop. Dit betekent dat GPWH en de deelregio's, evenals de Nederlandse glastuinbouw als geheel, netto elektriciteitsleverancier waren.

Kijken we naar de afzonderlijke deelregio's dan blijkt in Zuid relatief minder elektriciteit te worden geconsumeerd. Ook de productie, verkoop en inkoop is hier relatief kleiner. De lagere consumptie hangt samen met de gemiddeld minder energie-intensieve teelten met minder belichting in deelregio Zuid (paragraaf 2.4).

Tabel 2.3 Globale elektriciteitsbalans glastuinbouw in GPWH en in Nederland in 2016

\begin{tabular}{|c|c|c|c|c|c|c|}
\hline \multirow[t]{2}{*}{ Elektriciteit } & \multirow[t]{2}{*}{ Eenheid } & \multicolumn{4}{|c|}{ GPWH } & \multirow[t]{2}{*}{ Nederland } \\
\hline & & West & Oost & Zuid & Totaal & \\
\hline Inkoop & Miljard kWh & 1,01 & 0,46 & 0,06 & 1,52 & 2,70 \\
\hline Verkoop & Miljard kWh & 1,44 & 0,61 & 0,16 & 2,21 & 4,95 \\
\hline Consumptie & Miljard kWh & 2,23 & 1,02 & 0,13 & 3,39 & 5,98 \\
\hline
\end{tabular}




\subsection{Energie per $\mathrm{m}^{2}$ kas}

Uit het totaal energiegebruik per $\mathrm{m}^{2}$ kas (tabel 2.4) blijkt dat in de glastuinbouw in GPWH gemiddeld energie-intensievere gewassen werden geteeld dan landelijk. Binnen GPWH geldt dat ook voor de deelregio's West en Oost. In Zuid werden gemiddeld energie-extensievere gewassen geteeld. Hierbij is ook het gebruik van belichting van invloed.

Ook bij de indicatoren per $\mathrm{m}^{2}$ blijkt de relatief grotere input van warmte (restwarmte en duurzame warmte) in regio oost. In totaal GPWH is was de gemiddelde warmte-input vrijwel gelijk aan het landelijk niveau.

In deelregio Oost werd er gemiddeld minder elektriciteit per $\mathrm{m}^{2}$ verkocht, ondanks dat er minder belichting werd gebruikt. Dit hangt samen met de inkoop van restwarmte in deze deelregio. Door beschikbaarheid van warmte is er minder wkk in gebruik.

Tabel 2.4 Diverse indicatoren glastuinbouw in GPWH en in Nederland in 2016 (gemiddeld per $m^{2}$ kas)

\begin{tabular}{|c|c|c|c|c|c|c|}
\hline \multirow[t]{2}{*}{ Indicatoren } & \multirow[t]{2}{*}{ Eenheid } & \multicolumn{4}{|c|}{ GPWH } & \multirow[t]{2}{*}{ Nederland } \\
\hline & & West & Oost & Zuid & Totaal & \\
\hline Energie totaal & $\mathrm{GJ} / \mathrm{m}^{2}$ & 1,2 & 1,2 & 0,9 & 1,2 & 1,1 \\
\hline Inkoop elektriciteit a) & $\mathrm{kWh} / \mathrm{m}^{2}$ & 38 & 35 & 18 & 35 & 29 \\
\hline Verkoop elektriciteit a) & $\mathrm{kWh} / \mathrm{m}^{2}$ & 54 & 47 & 52 & 51 & 53 \\
\hline
\end{tabular}

a) inclusief duurzame elektriciteit; b) omvat restwarmte, warmte van wkk van energiebedrijven en duurzame warmte.

\subsection{Energie-indicatoren}

\section{$\mathrm{CO}_{2}$-emissie}

De $\mathrm{CO}_{2}$-emissie van de glastuinbouw in GPWH als geheel bedroeg in 2016 2,8 Mton (tabel 2.5) en omvatte $49 \%$ van de $\mathrm{CO}_{2}$-uitstoot van de gehele Nederlandse glastuinbouw. Het aandeel van het areaal in GPWH omvat 46\% van het landelijk areaal. Het verschil hiertussen hangt samen met de gemiddeld hogere energievraag en het grotere aandeel van de energievoorziening zonder $\mathrm{CO}_{2}$-emissie in GPWH. Het voorgaande betekent dat de grotere energievraag dus niet in $z^{\prime} n$ geheel werd gecompenseerd door de grotere energievoorziening zonder $\mathrm{CO}_{2}$-emissie.

In deelregio West was het aandeel in de landelijke $\mathrm{CO}_{2}$-emissie van de glastuinbouw 33\%, in Oost was dat $13 \%$ en in Zuid $3 \%$. In West was dit aandeel groter dan het aandeel in het totaal areaal glastuinbouw in Nederland (29\%) en in oost was dat kleiner (14\%). Deze verschillen tussen de deelregio's hangen samen met de totale energie-intensiteit per $\mathrm{m}^{2}$ en het aandeel van de energievoorziening zonder $\mathrm{CO}_{2}$-emissie.

Het voorgaande komt ook tot uiting in de gemiddelde $\mathrm{CO}_{2}$-uitstoot per $\mathrm{m}^{2}$ kas. In GPWH lag in 2016 de $\mathrm{CO}_{2}$-emissie met $69 \mathrm{~kg} / \mathrm{m}^{2}$ hoger dan landelijk $\left(61 \mathrm{~kg} / \mathrm{m}^{2}\right)$. Binnen $\mathrm{GPWH}$ was de $\mathrm{CO}_{2}$-emissie per $\mathrm{m}^{2}$ met $74 \mathrm{~kg} / \mathrm{m}^{2}$ het grootst in deelregio West. In Oost $\left(57 \mathrm{~kg} / \mathrm{m}^{2}\right)$ en Zuid $\left(55 \mathrm{~kg} / \mathrm{m}^{2}\right)$ lag dit zowel onder het gemiddelde van GPWH als van de gehele Nederlandse glastuinbouw. 
Tabel 2.5 Energie-indicatoren glastuinbouw in GPWH en in Nederland in 2016

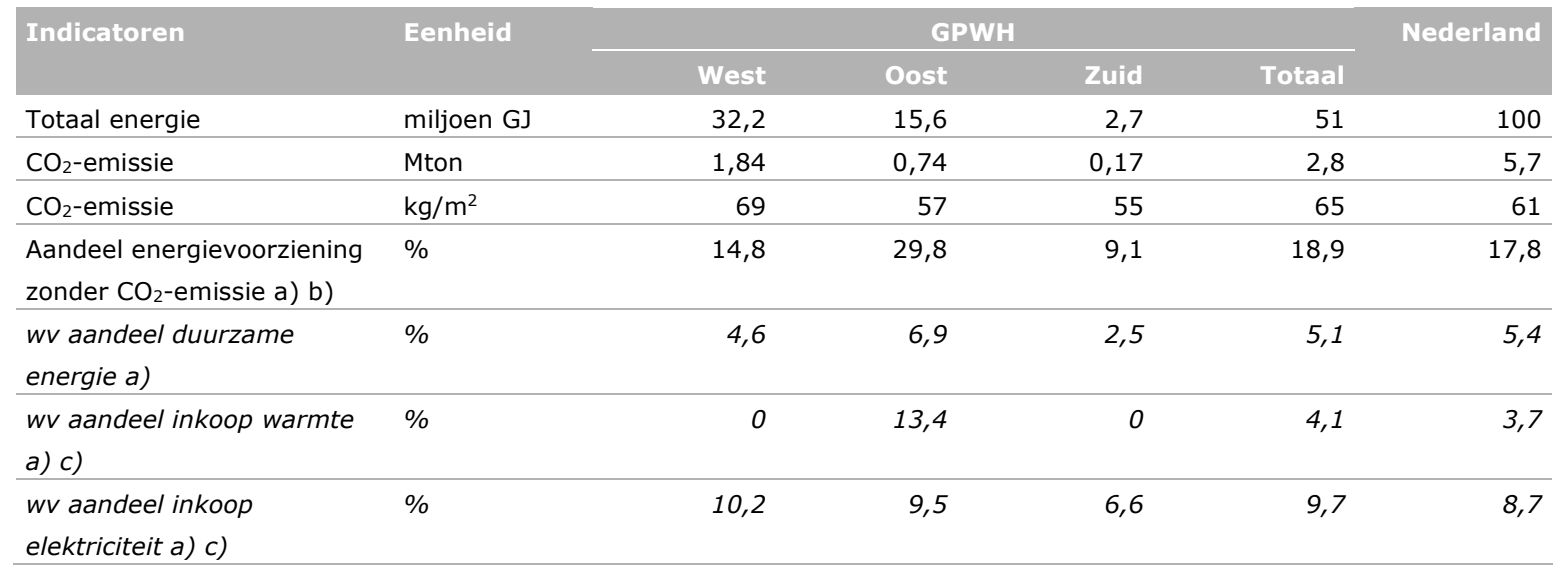

a) aandeel in het totaal netto-energiegebruik; b) omvat duurzame energie, inkoop warmte en inkoop elektriciteit; c) exclusief duurzaam.

Aandeel energievoorziening zonder $\mathrm{CO}_{2}$-emissie

Het aandeel van de energievoorziening zonder $\mathrm{CO}_{2}$-emissie in het netto energiegebruik omvat duurzame energie, inkoop warmte en inkoop elektriciteit. Deze 3 elementen zijn hierna behandeld. Ter voorkoming van dubbeltellingen zijn de laatste 2 elementen exclusief duurzame energie.

Het totaal aandeel was in GPWH met 18,9\% groter dan het landelijk aandeel $(17,8 \%$ ) (figuur 2.2 en tabel 2.5$)$. In deelregio Oost $(29,8 \%)$ zat dit duidelijk boven het niveau van geheel Nederland en in West $(14,8 \%)$ en Zuid $(9,1 \%)$ lag dat eronder. Dit komt vooral door het restwarmteproject in de deelregio Oost. Daarnaast was ook het aandeel duurzame energie groter in deelregio Oost.

\section{Aandeel duurzame energie}

Het aandeel duurzame energie in het totaal energiegebruik bedroeg in 2016 in GPWH 5,1\% (tabel 2.5). Dit was lager dan in de gehele Nederlandse glastuinbouw (5,4\%). In de deelregio Oost was het aandeel duurzame energie $(6,9 \%)$ groter en in West $(4,6 \%)$ en Zuid $(2,5 \%)$ kleiner dan in geheel GPWH en in de gehele Nederlandse glastuinbouw.

\section{Aandeel inkoop warmte}

Het aandeel inkoop warmte door de glastuinbouw was in GPWH hoger $(4,1 \%)$ dan landelijk $(3,7 \%)$ (tabel 2.5). De inkoop warmte zat volledig in deelregio Oost en dit komt door het warmteleveringsproject in deze deelregio. In regio Oost bedroeg het aandeel $13,5 \%$.

\section{Aandeel inkoop elektriciteit}

Het aandeel inkoop elektriciteit in het totaal energiegebruik bedroeg in GPWH 9,7\% (tabel 2.5). Dit was hoger dan in de Nederlandse glastuinbouw $(8,7 \%)$. In de deelregio West lag het aandeel boven dat van GPWH en van Nederland. In Zuid lag dat eronder. 


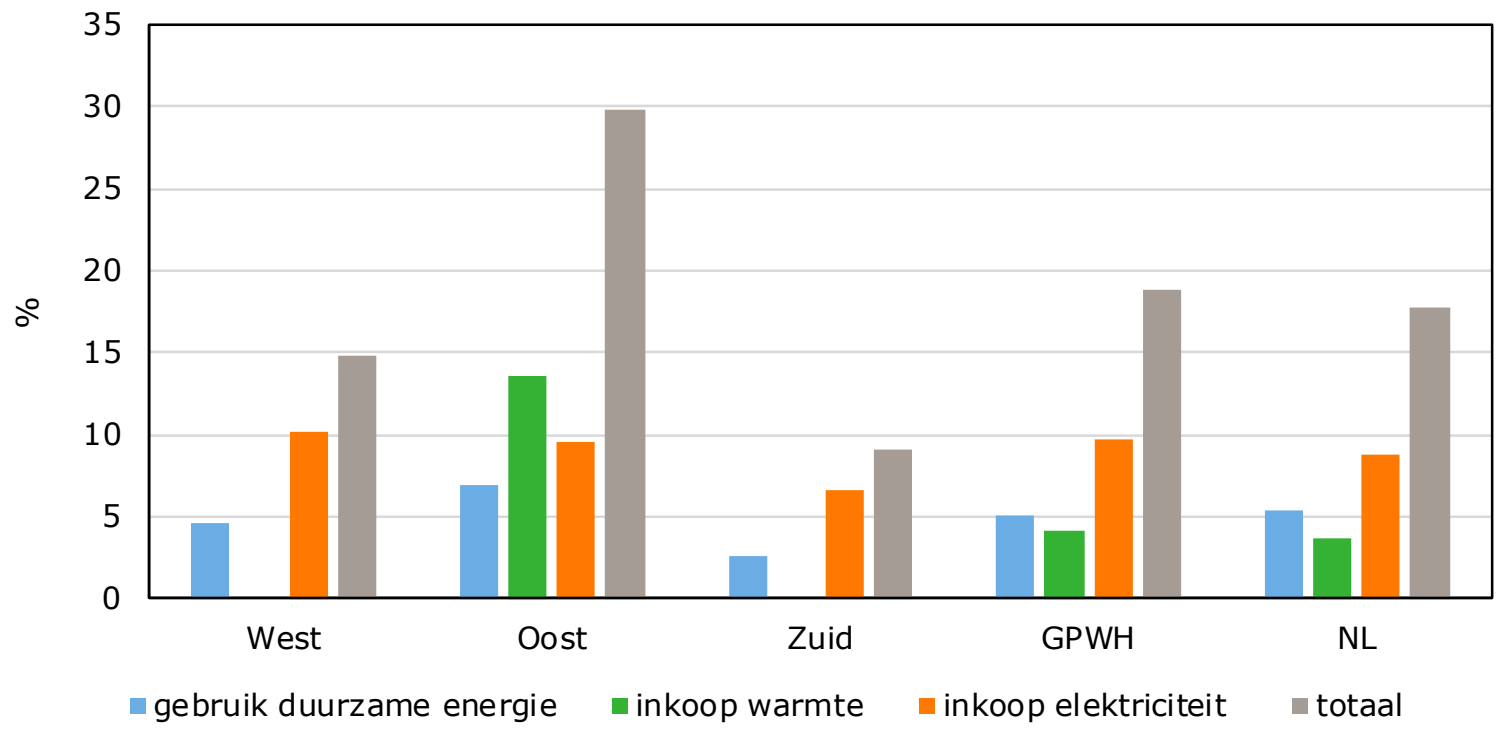

Figuur 2.2 Aandelen energievoorziening zonder $\mathrm{CO}_{2}$-emissie in het netto energiegebruik in GPWH en Nederland 


\section{Literatuur en websites}

Brief van de Staatssecretaris van Economische Zaken, dd. 6 juli 2017, betreft Evaluatie $\mathrm{CO}_{2}$-sturing in de glastuinbouw.

Energieakkoord voor duurzame groei, SER, 2013.

Energieakkoord Westland-Oostland, inclusief programmaplan, 5 oktober 2017

Meerjarenafspraak Energietransitie Glastuinbouw 2014-2020, Den Haag, 2014

Smit, P.X. en N.J.A. van der Velden, Energieverduurzaming Westlandse glastuinbouw: Van middenmoter naar koploper (deel 2), Rapport 2016-086, Wageningen Economic Research, Den Haag, 2016.

Smit, P.X.; Velden, N.J.A. van der, Kompas op 2030; Verduurzamingsrichtingen energievoorziening Westlandse glastuinbouw. Rapport 2018-111, Wageningen Economic Research, Wageningen, 2018.

Smit, P.X.; Velden, N.J.A. van der, Energieverduurzaming Oostlandse glastuinbouw 2030; Wageningen Economic Research, Wageningen, in voorbereiding.

Velden, N.J.A. van der en P.X. Smit, Effect intensivering, extensivering en energiebesparing op de $\mathrm{CO}_{2}$-emissie van de Nederlandse glastuinbouw. Rapport 2017-060. Wageningen Economic Research, Wageningen, 2017.

Velden, N.J.A. van der, P.X. Smit en J.S. Buurma, Prognoses $\mathrm{CO}_{2}$-emissie glastuinbouw 2030. Rapport 2018-056. Wageningen Economic Research, Wageningen, 2018.

Velden, N.J.A. van der en P.X. Smit, Energiemonitor van de Nederlandse Glastuinbouw 2018. Rapport 2018-109. Wageningen Economic Research, Wageningen, 2018a.

Velden, N.J.A. van der en P.X. Smit, Protocol Energiemonitor Glastuinbouw; Versie tot en met 2017. Nota 2018.109a. Wageningen Economic Research, Wageningen, 2018b.

Velden, N.J.A van der en P.X Smit, Conceptueel raamwerk Regionale Energiemonitor Glastuinbouw. Nota 2019.061. Wageningen Economic Research, Wageningen, 2019. 


\section{Bijlage 1 Gemeenten per deelregio in GPWH 2016 a)}

\begin{tabular}{lll} 
West & & \\
Den Haag & Oost & Zuid \\
\hline Maassluis & Delft & Alblasserwaard \\
\hline Midden-Delfland & Lansingerland & Barendrecht \\
\hline Rotterdam & Pijnacker-Nootdorp & Binnenmaas \\
\hline Schiedam & Waddinxveen & Brielle \\
\hline Vlaardingen & Zuidplas & Cromstrijen \\
\hline Westland & & Hellevoetsluis \\
\hline & & Hendrik Ido Ambacht \\
\hline & & Korendijk \\
\hline & Nissewaard \\
\hline & & Oud Beijerland \\
\hline & Ridderkerk \\
\hline & Strijen \\
\hline
\end{tabular}

a) In de nulmeting voor GPWH is ook het glasareaal in een aantal gemeenten opgenomen die formeel niet tot de GPWH behoren. Het gaat veelal over een beperkt areaal maar de Greenport-gerelateerde bedrijven in deze gemeenten zijn in hun bedrijfsvoering en activiteiten over het algemeen wel te beschouwen als onderdeel van Greenport West-Holland. 
Wageningen Economic Research Postbus 29703

2502 LS Den Haag

T 0703358330

Ecommunications.ssg@wur.nl

www.wur.nl/economic-research

Wageningen Economic Research NOTA

2019-060
De missie van Wageningen University \& Research is 'To explore the potential of nature to improve the quality of life'. Binnen Wageningen University \& Research bundelen Wageningen University en gespecialiseerde onderzoeksinstituten van Stichting Wageningen Research hun krachten om bij te dragen aan de oplossing van belangrijke vragen in het domein van gezonde voeding en leefomgeving. Met ongeveer 30 vestigingen, 5.000 medewerkers en 10.000 studenten behoort Wageningen University \& Research wereldwijd tot de aansprekende kennisinstellingen binnen haar domein. De integrale benadering van de vraagstukken en de samenwerking tussen verschillende disciplines vormen het hart van de unieke Wageningen aanpak. 



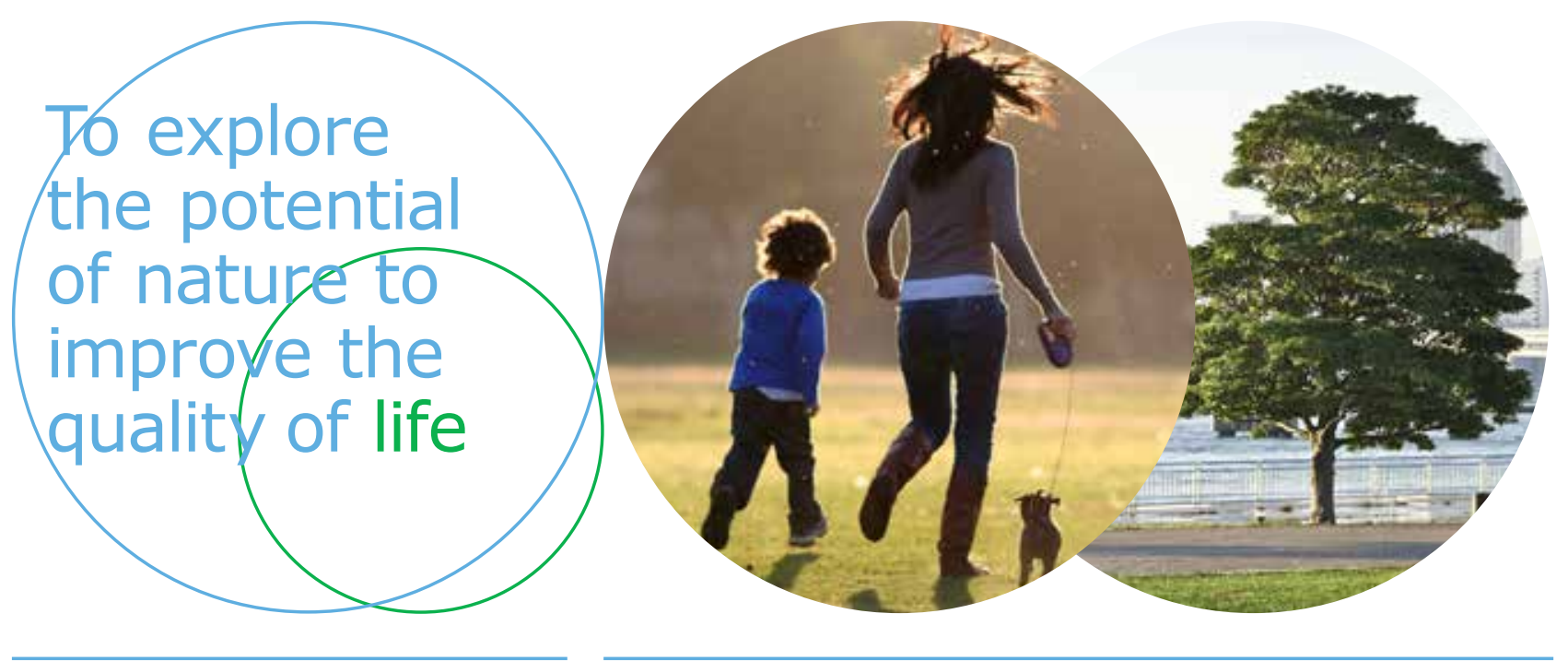

Wageningen Economic Research Postbus 29703

2502 LS Den Haag

E communications.ssg@wur.nl

T+31(0)7033583 30

www.wur.nl/economic-research

Nota $2019-060$
De missie van Wageningen University \& Research is 'To explore the potential of nature to improve the quality of life'. Binnen Wageningen University \& Research bundelen Wageningen University en gespecialiseerde onderzoeksinstituten van Stichting Wageningen Research hun krachten om bij te dragen aan de oplossing van belangrijke vragen in het domein van gezonde voeding en leefomgeving. Met ongeveer 30 vestigingen, 5.000 medewerkers en 10.000 studenten behoort Wageningen University \& Research wereldwijd tot de aansprekende kennisinstellingen binnen haar domein. De integrale benadering van de vraagstukken en de samenwerking tussen verschillende disciplines vormen het hart van de unieke Wageningen aanpak. 